\title{
The impact of active surveillance cultures in reducing methicillin-resistant Staphylococcus aureus infections in a surgical intensive care unit in Singapore
}

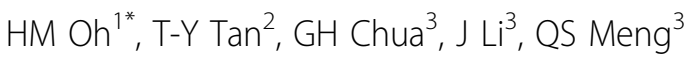 \\ From International Conference on Prevention \& Infection Control (ICPIC 2011) \\ Geneva, Switzerland. 29 June - 2 July 2011
}

\section{Introduction / objectives}

Infection and colonization with methicillin-resistant Staphylococcus aureus (MRSA) is associated with significant morbidity and mortality. To study the impact of active surveillance cultures (ASC), environmental cleaning and decolonization regimen in reducing MRSA infections in Surgical Intensive Care Unit (SICU).

\section{Methods}

The study was conducted in SICU. ASCs were performed from 20 Sep 10 to 28 Feb 11 on all patients admitted/ transferred in/transferred out of SICU. ASC specimens consisted of swabs from anterior nares and axilla/groin. The swabs were inoculated onto chromogenic agar selective for MRSA (MRSASelect, Bio-Rad). MRSA positive patients were placed on contact precautions/isolation. Automatic hand sanitizers were installed in SICU to increase hand hygiene compliance. The decolonization regimen consisted of mupirocin ointment tds and daily Prontoderm ( $0.1 \%$ polyhexanide) for 5 days. Sureclean, an ionic silver disinfectant lasting 24 hours was used for environmental disinfection.

\section{Results}

453 patients were screened on entry/transfer in. 45 patients $(9.9 \%)$ were detected to be MRSA colonized on entry. 214 patients were screened on transfer out/death. 9 patients (4.2\%) acquired MRSA on exit. There were 10 skin, 29 nasal and 15 skin/nasal carriers. There was an increase in overall hand hygiene compliance from $68.4 \%$ in Sep 10 to $90.9 \%$ in Feb 11. The incidence of MRSA Infection was reduced from 1.7/1000 patient days (Mar Aug 10) to 0.9/1000 patient days (Sep 10 - Feb 11).

\section{Conclusion}

We demonstrated a significant reduction of MRSA Infections in SICU with implementation of ASC.

\section{Disclosure of interest}

None declared.

\section{Author details}

${ }^{1}$ Medicine, Changi General Hospital, Singapore, Singapore. ${ }^{2}$ Laboratory Medicine, Changi General Hospital, Singapore, Singapore. ${ }^{3}$ Infection Control Unit, Changi General Hospital, Singapore, Singapore.

Published: 29 June 2011

\section{doi:10.1186/1753-6561-5-S6-P233}

Cite this article as: Oh et al:: The impact of active surveillance cultures in reducing methicillin-resistant Staphylococcus aureus infections in a surgical intensive care unit in Singapore. BMC Proceedings 2011 5(Suppl 6):P233.

${ }^{1}$ Medicine, Changi General Hospital, Singapore, Singapore

Full list of author information is available at the end of the article

(c) 2011 Oh et al; licensee BioMed Central Ltd. This is an open access article distributed under the terms of the Creative Commons Attribution License (http://creativecommons.org/licenses/by/2.0), which permits unrestricted use, distribution, and reproduction in any medium, provided the original work is properly cited. 